\title{
Tecendo diálogos: Han Kang, Van Gogh e Henri Meschonnic
}

\author{
Weaving dialogues: Han Kang, \\ Van Gogh and Henri Meschonnic
}

Maria Sílvia Cintra Martins*

\footnotetext{
* Professora Sênior do Departamento de Letras da Universidade Federal de São Carlos. Atua nos programas de pós-graduação PPGL/UFSCar e LETRA/USP. É pesquisadora PQ-2 (CNPQ) e participa do Projeto "Rhythmuskonzept in der Translation und Translationswissenschaft" (Universidade de Hildesheim/Alemanha), voltado ao aprofundamento e detalhamento na pesquisa em torno da obra de Henri Meschonnic. E-mail: msilviamart@gmail.com

TradTerm, São Paulo, v.38, fevereiro/2021, p. 22-45

Número Especial - III JOTA

www.revistas.usp.br/tradterm
} 
Resumo: Neste trabalho, busco esclarecimentos a respeito de diferentes obras de diferentes autores por meio da metodologia do 'jogo de espelhos' (MARTINS 2020), que possui afinidade com os estudos comparados e é tributária do paradigma indiciário (GINZBURG 1989). Aspectos teóricos da proposta da Antropologia da Linguagem, do linguista, poeta e tradutor francês Henri Meschonnic, são colocados em diálogo, primeiro com a obra Leçons de Grec (KANG 2019); em seguida com trecho da carta 179 de Van Gogh (VAN GOGH MUSEUM 2009). Obtenho, dessa forma, certos esclarecimentos a respeito da proposta literária da escritora coreana Han Kang; de eventual projeto de tradução para a carta 179 do pintor holandês Vincent Van Gogh, a qual ainda não possui tradução para a língua portuguesa; também, de aspectos ainda não muito bem compreendidos e difundidos da obra de Henri Meschonnic.

Palavras-chave: Jogo de espelhos; Panrítimica; Silêncio; Poema; Leçons de Grec

Abstract: In this paper, I search a better understanding about different works realized by different authors employing the methodology of the 'play of mirrors' (MARTINS 2020), with similarities with compared studies and tributary of evidential paradigm (GINZBURG 1989). Some theoretical aspects of the Anthropology of Language, defended by French linguist, poet and translator Henri Meschonnic are set in dialogue first with the novel Leçons de Grec (KANG 2019); after with excerpts from the letter 179 by Van Gogh (VAN GOGH MUSEUM 2009). I thus obtain some insights: on the literary proposal of the Korean writer Han Kang; on an eventual project of translation for the letter 179 written by the Dutch painter Vincent Van Gogh, which has not received so far a translation into the Portuguese language; also on some aspects of Henri Meschonnic's theory which have not yet been completely understood and diffused.

Keywords: The Play of Mirrors; Panrhythm; Silence; Poem; Leçons de Grec.

TradTerm, São Paulo, v.38, fevereiro/2021, p. 22-45

Número Especial - III JOTA

www.revistas.usp.br/tradterm 


\section{Introdução}

Há algum tempo venho optando pela escrita de textos acadêmicos que mesclam reflexões típicas dos textos argumentativos com relatos de caráter mais pessoal e empírico. Também criei uma forma de trabalho intelectual que coloca frente a frente diferentes autores em busca de um diálogo possível (MARTINS 2020). Denomino essa estratégia metodológica de 'jogo de espelhos' ('play of mirrors'), que entendo ser de caráter indutivo, interpretativo e tributário do paradigma indiciário (GINZBURG 1989). Este trabalho comportará essa dupla estratégia.

Vale notar que a eventual sensação de um disparate ao se porem frente a frente, ou em conjunto, autores tão diferentes - como a escritora coreana Han Kang, o pintor holandês Van Gogh e o poeta, linguista e tradutor francês Henri Meschonnic - decorre da falta de compromisso e de alinhamento com a lógica mais convencional, discreta e linear, em favor da busca de continuidades, mesmo onde, em princípio, pareceria não haver.

Ponho-me, de início, a ler Leçons de Grec, a tradução para o francês da obra de Han Kang Hirabô shigan, de 2011. Isso porque uma de minhas orientandas de doutorado, Ji Kim, de nacionalidade coreana, propôs-se a desenvolver sua tese na tradução do original de Han Kang para o português, cabendo-me conhecê-lo, mesmo que em língua diversa. Dessa forma, todas as referências que faço, aqui, à obra de Kang dizem respeito à sua versão em língua francesa, e não ao original.

Pensar sobre as traduções é sempre muito interessante, mesmo porque podemos, ao ler um livro traduzido, ter a sensação de que estaria bem ou mal traduzido independentemente de conhecer sua versão original. Ao menos uma primeira avaliação se faz possível assim, e foi uma sensação positiva que tive ao ler a proposta de Jeong Eun-Jin e Jacques Batilliot em Leçons de Grec. 0 texto flui, o texto convence em sua qualidade literária, e isso se dá pela minuciosa escolha vocabular, mas, certamente, também, pela organização frástica, sintagmática.

Difícil articulação, essa, à qual damos o nome de ritmo, de panrítmica. Panrítmica que se associa com o sujeito do poema, entendendo-se 'poema' TradTerm, São Paulo, v.38, fevereiro/2021, p. 22-45

Número Especial - III JOTA

www.revistas.usp.br/tradterm 
em sentido amplo, que transcende a subdivisão entre poesia e prosa (MESCHONNIC 1982; 2006a). O sujeito do poema, por sua vez, não se confundiria com o sujeito da enunciação, exatamente por estar entranhado na linguagem, por ser interior a ela, por ser da ordem do linguístico. Em meu entender, de toda forma, o sujeito do poema, no caso do romance de Han Kang, se constrói de forma prismática, na medida em que se alternam os personagens e suas narrativas pessoais, assim como as modalidades ou gêneros de seus discursos, ora dentro do teor das memórias, ora de forma epistolar, ora em trechos de conversas pessoais. Há momentos, ainda, em que parece que é a autora propriamente dita quem assume a palavra.

Nesse sentido, percebe-se que estamos diante de um enorme desafio de tradução, de modo que muito provavelmente a tradução para a língua portuguesa também carecerá de trabalho ao menos de um nativo de cada uma das línguas, e com bastante sensibilidade para perceber e traduzir essas diferentes nuanças.

Mais tarde, visito a carta 179 de Van Gogh a seu irmão Theo (VAN GoGH MUSEUM 2009), no original em holandês e na tradução para o inglês - desta feita sob demanda da orientação de uma dissertação de Mestrado, para a qual Naia da Silveira apresenta a hipótese de que as cartas de Van Gogh merecem um tratamento literário. Naia escolheu, de início, quinze cartas do acervo do Museu Van Gogh, pelo fato de todas elas versarem sobre a paixão do pintor holandês por sua prima Kee. Dentre elas, a carta 179 foi tida como representativa dessa fase da vida do autor.

Dessa forma, posso dizer que foi até certo ponto aleatória a escolha do romance e da carta para propor o jogo de espelhos com conceitos provindos da obra de Meschonnic. Só até certo ponto, porque os conceitos em questão já visitavam meu corpo e minha mente quando me deparei com essas obras, e pude encontrar nelas algumas representações daquilo que o teórico francês tematiza.

Passamos, primeiro, a reflexões em torno do diálogo que construo entre Kang e Meschonnic - diálogo construído e proposto por mim, à medida que visito, de forma casual, um e outro autor - para só ao final nos dedicarmos a

TradTerm, São Paulo, v.38, fevereiro/2021, p. 22-45

Número Especial - III JOTA

www.revistas.usp.br/tradterm 
alguns aspectos da tradução, do holandês para o inglês, da carta 179, de Van Gogh a seu irmão Theo, sobre a qual, propositalmente, me debruço de forma mais pontual, na observação da escolha de palavras por parte do tradutor e na ponderação sobre possibilidades de tradução para a língua portuguesa.

Em ambos os casos, são os conceitos de ritmo e de panrítmica, em particular, aos quais o linguista francês atribui destaque em diversas obras seja em Meschonnic (2010), uma das poucas obras suas que já circulam em língua portuguesa em nosso país - que busco iluminar e esclarecer.

\section{Silêncio: Linguagem}

O texto de Han Kang (2019) fala do silêncio, e constrói-se na alternância entre o dizer e o calar. É frequente o não dito, o quase dito, assim como o calar-se.

Porém, o que se faz próprio da poiesis não é aquilo de que se fala, mas o como se trata disso. E a aliança que se constrói entre aquilo de que se (talvez) pretenda falar, e a forma que comporta esse dizer. Segundo Meschonnic (2006a; 2008; 2010), trata-se do que fazemos com a linguagem, e a tradução trai - e sempre trai - mas trai de forma mais definitiva se não der conta dessa torção com a linguagem (MARTINS 2020).

Ou seja, para traduzir o texto de Han Kang, não basta que o tradutor transporte para o leitor esse tema do silêncio nas palavras da outra língua mesmo porque esse não foi o gesto inicial, fundador (se é que podemos falar assim) da autora. Por isso mesmo, reconhecemos em Kang uma literata, e não uma física ou uma psicóloga que estivesse tematizando o silêncio. 0 texto de Han Kang faz-se de silêncios. Os quais, em parte - mas apenas em parte - são construídos pelos espaçamentos e pelos asteriscos que o texto comporta - e essa seria a parte mais evidente para uma eventual tradução.

Há outra parte que se constrói por pontuações, por tonicidades, por fechamentos de palavras, de frases e de parágrafos. Não estamos diante de um poema em seu sentido convencional: há, de toda forma, aí, algo que

TradTerm, São Paulo, v.38, fevereiro/2021, p. 22-45

Número Especial - III JOTA

www.revistas.usp.br/tradterm 
recende a uma métrica, mas que se faz melhor compreender pelo conceito embora fugidio - de panrítmica.

Como texto pertencente à literatura contemporânea, a proposta de Han Kang, entre outros aspectos, fala de literatura pela literatura. E nos fala da necessidade da escuta (MESCHONNIC 2006A). O professor, personagem que se apresenta praticamente cego e relata à jovem aluna de grego antigo, em capítulo próximo ao final, a forma com que, progressivamente, se tornou cego, retomando suas memórias (enquanto ela, silenciosamente, retoma as suas), pergunta com frequência a sua interlocutora (ou melhor, àquela que lhe estaria à escuta, já que esta, por sua vez, perdeu a capacidade ou talvez o desejo da fala, em dado momento de sua vida):

- Êtes-vous toujours là à m'écouter?

- Vous m'écoutez?

- ... M'entendez-vous? (KANG 2019: 162 e 170). ${ }^{1}$

O narrador já nos havia apresentado a esse silêncio da personagem, ou a essa personagem-silêncio: “C'est un silence froid et dilué, comme une ombre ayant perdu son corps, comme le tronc creux d'un arbre mort, comme l'espace obscur entre deux planètes" (KANG 2019: 20). ${ }^{2}$

A personagem de Kang questiona o diagnóstico de seu psicanalista, e responde-lhe, por escrito, quando ele busca explicações para seu mutismo em traumas do passado: “Ce n'est pas si simple que ça" ("Não é tão simples assim”) (KANG 2019: 56). Aponta, de preferência (sem compartilhar com ele, no entanto), para questões que têm a ver com seu próprio corpo, hoje, com o mundo ao redor e com o funcionamento da linguagem. Com a historicidade, se quisermos abrir o diálogo com Meschonnic (2006a), o qual também, de resto, faz restrições à Psicanálise, como à Antropologia, à Sociologia e à Filosofia particularmente no que se refere a sua possibilidade de crítica genuína, como também no que tange ao fato de essas áreas do conhecimento não darem conta, em seu entender, do sujeito do poema (que não seria o sujeito da

1 "Você continua me ouvindo? / Você está me ouvindo? / ... Você está me escutando? ". Noto que são minhas todas as traduções aqui presentes do francês para o português.

2 "É um silêncio frio e difuso, como a sombra que perdeu seu corpo, como o tronco oco da árvore morta, como o espaço obscuro entre dois planetas".

TradTerm, São Paulo, v.38, fevereiro/2021, p. 22-45

Número Especial - III JOTA

www.revistas.usp.br/tradterm 
enunciação) e por não pressuporem em suas reflexões e teorizações um funcionamento específico, que é o funcionamento da linguagem.

Tanto a escritora coreana, quanto o linguista francês travam o combate - cada um com os recursos próprios à modalidade de escrita que escolheram contra o mecanicismo da abordagem discreta, a qual insiste nas ligações e explicações que unem e separam causa e efeito dentro de um percurso histórico diacrônico, em que cada fato ocuparia certa posição em dada taxonomia desprovida de vasos comunicantes. O que passou passou.

A personagem feminina, desprovida de nome, desesperada - e ao mesmo tempo serena - por não haver conseguido a guarda de seu filho, declara a nós, seus leitores:

Rien ne cicratize jamais.

Rien n'est jamais fini (KANG 2019: 64). ${ }^{3}$

Trata-se de uma fala que, na verdade, pode pertencer a ela, como ao narrador, como mesmo à autora. Kang constrói seu romance de uma forma sugestiva e difusa que nos permite levantar essas dúvidas e essas hipóteses.

Aparentemente, no entanto, a perda da guarda do filho de oito anos não seria a causa da perda da linguagem, que parece até mais proposital e anterior a todo desespero.

Em certa passagem, a explicação estaria em seu modo discreto de ser, pouco invasivo, e em sua vontade de não se sentir ocupando espaço. As palavras se proliferam, irradiam, se propagam para fora de nós mesmos. Em outra passagem, haveria uma opção por uma visão de mundo desprovida de palavras:

Elle se contente de regarder. Regardant, elle ne traduit rien de ce qu'elle aperçoit en langage.

Les images de différents objets se reflètent dans ses yeux, avant de s'effacer dans le mouvement, à la vitesse de sa marche. Disparaissant, elles ne se traduisent en aucun langage (KANG 2019: 69). ${ }^{4}$

\footnotetext{
3 "Nada cicatriza, nunca. Nada nunca tem fim".

4 "Ela se contenta com olhar. Olhando, não traduz nada do que percebe em linguagem./ As imagens dos diferentes objetos refletem-se em seus olhos, e se desmancham com o TradTerm, São Paulo, v.38, fevereiro/2021, p. 22-45

Número Especial - III JOTA www.revistas.usp.br/tradterm
} 
Vinte e cinco páginas à frente, aparece a questão da valoração, intimamente ligada à tradução de sensações em palavras. Já começara a haver certa aproximação bastante sóbria entre os dois personagens, o professor de grego antigo e a aluna de seus trinta anos. Era reconhecível certa transformação na aparência do professor: antes, alguém comum; agora, de rosto e expressões familiares. Porém, por não traduzir essa transformação em linguagem, ela mesma não lhe atribui nenhuma importância (KANG 2019: 94).

Dentre as diversas passagens que versam sobre o silêncio da personagem feminina, numa delas aparece seu desejo por uma palavra (cristal) que condensaria em si todas as línguas: "Un mot compressé avec une densité et une gravité prodigieuses. La parole qui, si quelqu'un s'avisait de la prononcer, gonflerait immédiatement et exploserait comme la matière à l'origine du monde" (KANG 2019: 21-22). ${ }^{5}$

Nesse universo romanesco em que os personagens às vezes se confundem, podemos pressentir, nesse momento (como em outros), a superposição entre a voz (e o eventual desejo) da autora e o pensamento e desejo de sua personagem.

Kang abre espaços de escritura em seu texto, dilacera-o, atribuindo-lhe como que o compasso de uma câmera lenta. 0 corpo abre espaços no tempo.

No percurso do texto de Kang, perdemo-nos, às vezes, no reconhecimento de quem é quem, já que a autora constrói certo perspectivismo no qual, vez ou outra, ela própria parece habitar momentaneamente as falas de personagens. Seja no capítulo 5, Voix (Vozes), em que, talvez apenas com um possível retorno, reconhecemos que se trata de uma carta do professor dirigida à filha do médico com quem se tratara numa clínica, e por quem nutrira seu amor adolescente. Tratando da cegueira na qual ingressa progressivamente, pondera:

movimento, no ritmo da caminhada. Ao desaparecer, não se traduzem em nenhuma linguagem".

5 "Uma palavra comprimida em densidade e gravidade prodigiosas. A palavra que, se alguém ousasse pronunciar, inflaria e explodiria de imediato, assim como a matéria no início do mundo".

TradTerm, São Paulo, v.38, fevereiro/2021, p. 22-45

Número Especial - III JOTA

www.revistas.usp.br/tradterm 
On devient avant tout plus sensible aux heures qui passent. Je me sens progressivement écrasé par la sensation du temps qui traverse en permanence mon corps et qui ressemble au cours lent et inexorable d'une coulée de boue (KANG 2019: 39). ${ }^{6}$

Platão ganha tempo na escrita da República, que a personagem coteja em suas diferentes versões, em grego e em coreano, e Kang ganha (ou abre) o tempo de sua escrita em descrições que fornecem ritmo desacelerado e reflexivo a sua escritura: "Elle serre le crayon. Expire prudemment. Supporte que l'émotion véhiculée par cette phrase apparaisse comme une trace de craie, une trace de sang séchée et oubliée" (KANG 2019: 60). ${ }^{7}$

O capítulo inicial de La Rime et La Vie denomina-se Silence: Langage, "Silêncio: Linguagem", e encontramos:

A linguagem fala da linguagem. 0 que ela mais nos revela é aquilo que fazemos com ela. Por isso mesmo somos todos, da forma mais inteira, nós mesmos o conteúdo da linguagem. A linguagem é, a cada vez, o sujeito inteiro. Sua história. A qual compreende mais o que ele não diz do que o que diz. A questão será saber como isso se dá. $O$ incomunicado é aquilo que se comunica primeiro.

Por isso mesmo o ritmo, que não está em nenhuma palavra separadamente, mas em todas juntas, é o sabor do sentido. Sua física (MESCHONNIC 2006a: 17).

A importância da escuta. Escutar o silêncio e buscar entender o que significa. No caso da personagem de Kang (e decerto da própria Kang), no silêncio reside a busca de uma linguagem genuína: que não seja puro discurso a preencher o espaço; que seja forte, vigorosa, quase explosiva; que seja densa: como o silêncio. Já se pretendêssemos seguir a linha de pensamento do linguista francês, caberia escutarmos e traduzirmos o silêncio construído na escrita de Kang; ou, em outras palavras: dar conta da forma de Kang lidar com as palavras, de seu trabalho com elas, de como fala e cala por meio de palavras. E de como esse falar e calar, a câmera lenta, os espaçamentos, os ditos e não ditos, os dizeres sobre dizeres, o dizer e redizer de outra forma,

\footnotetext{
6 "Tornamo-nos, sobretudo, mais sensíveis às horas que passam. Eu me sinto progressivamente esmagado pela sensação do tempo que, permanente, atravessa meu corpo e que se assemelha ao curso lento e inexorável de um fluxo de lama".

7 "Ela aperta o lápis. Expira cuidadosamente. Suporta que a emoção veiculada por essa frase apareça como um rastro de giz, um rastro de sangue seco e esquecido".
}

TradTerm, São Paulo, v.38, fevereiro/2021, p. 22-45

Número Especial - III JOTA

www.revistas.usp.br/tradterm 
as repetições e os deslizamentos contribuem para compor a narrativa, fazendo que esta não se reduza a um eventual roteiro.

A língua e a gramática da língua, a língua viva e a língua morta: por que torneio conseguiria uma língua antiga e morta trazer à tona a língua elamesma, em sua força de energia viva?

A personagem, com base nas explicações do professor, trata de compor frases na linha dos exemplos apresentados em giz, na lousa. O colega flagra sua tentativa de compor frases na forma fornecida e entende tratar-se de um poema. Mas como podem frases compostas com base em modelos transformarse em poemas? Um enigma para o leitor resolver.

\section{Modernidade}

No cenário que se constrói por trás da narrativa principal, de forma aleatória e como que sem nenhum propósito maior, vamos encontrando, aqui e ali, o desenho de um quadro, de uma historicidade: a grande parte dos alunos sonolentos, desconcentrados e que planejam pedir ao professor o abrandamento nas avaliações; a estagiária que, cheia de excitação, mostra ao professor as novidades do celular que acaba de comprar; questões financeiras dos alunos e de suas famílias; o individualismo; as transformações de cidades como Suyuri, com o avanço de construções modernas; o desconhecimento e desvalorização da cultura clássica; o funcionamento acelerado da metrópole Seoul, com seus arranha-céus em que se destacam enormes informes publicitários:

Sur des visages agrandis des dizaines de fois remuent d'énormes lèvres qui disent des choses inaudibles. D'énormes caracteres défilent dans la partie inférieure comme autant de poissons remuant la bouche. Les images agrandies des actualités se succèdent (KANG 2019: 97). ${ }^{8}$

\footnotetext{
8 "Sobre rostos aumentados dezenas de vezes, agitam-se lábios enormes que pronunciam coisas inaudíveis. Caracteres enormes desfilam na parte inferior como um monte de peixes remexendo as bocas. Sucedem-se imagens aumentadas das notícias".
}

TradTerm, São Paulo, v.38, fevereiro/2021, p. 22-45

Número Especial - III JOTA

www.revistas.usp.br/tradterm 
De forma sutil e relativamente indireta, trata-se, também, das migrações contemporâneas e da perda das identidades que se mesclam na fragmentação da linguagem, no sentir-se estranho na língua estrangeira e no estranhamento resultante da volta a sua própria língua materna. Da discriminação e do racismo. Talvez Derrida (2001) de Prótese de origem contribua para pensar essa questão. E, certamente, também Meschonnic (2005), em “Oui, qu'appelle-t-on penser?”, que nos convida a um retomar do pensamento na retomada da linguagem: onde comparece a importância do poema, entendido latu sensu como uma forma específica, heurística, criativa de trabalhar com a linguagem.

Nesse sentido, aliás, não me pareceria, em princípio, que a aprendizagem de uma língua antiga, em seus meandros gramaticais, pudesse contribuir para esse gesto criativo - mas Kang aponta nuances de outra vertente, na medida em que sinaliza para a retomada de uma língua original, por assim dizer, uma língua/ linguagem que nos caberia retomar do passado em sua força-cristal, atualizando-a no presente. É, de resto, nessa direção, que o pensamento angustiado da personagem sobre sua vida pode ser lido, também, como a proposta de Kang para a Literatura: "Nada cicatriza, nunca. Nada nunca tem fim" (KANG 2019: 64). Cabe-nos lembrar, ainda, na busca de aprofundar o diálogo possível entre a Kang escritora e o Meschonnic poeta e ensaísta, daquele Meschonnic que leva adiante intuições benjaminianas (CAMPos, 1997), e que, à sua forma (e na forma-linguagem), estaria, ele próprio, em busca da língua pura tematizada por Benjamin (2011).

Conheci em conferência em Hildesheim, na Alemanha, no final de 2019, um jovem pesquisador, Shungo Morita, que desenvolve seu doutorado em Paris sob a orientação de Serge Martin - por sua vez, dos maiores conhecedores da obra de Henri Meschonnic, que foi seu orientador. Shungo vem cotejando a obra do Meschonnic tradutor com aquela do poeta, e mostrou-nos de que maneira a poesia autoral se deixa impregnar de traços das obras traduzidas. Um dos casos mencionados concerne à obra Et la terre coule (MESCHONNIC 2006b), em cujo título o jovem pesquisador apontou traços de versos da Ilíada, traduzidos por Meschonnic para o francês: "Ensemble montaient le cri 
de malheur et la clameur / des tueurs et des tués et la terre coulait de sang" (MESCHONNIC 1999: 110). ${ }^{9}$

Talvez por já ter essas questões na memória, me chamaram a atenção palavras e trechos que se repetem na obra de Kang. Um deles tem a ver com uma anotação do personagem/professor em livro de Borges. Borges teria escrito: “O universo é uma ilusão: viver é sonhar" e o professor (na época, estudante) anotara: “Comme ce rêve est vivant! Le sang coule et des larmes jaillissent” (KANG 2019: 28). Vale lembrar que se trata do professor de grego, certamente leitor da llíada no original. ${ }^{10}$

Nessa linha de pensamento, em que vemos que faz parte da poética de Kang a retomada e incorporação em sua obra de motivos presentes em outras obras - procedimento poético que em Martins (2018) apresento como uma vertente de 'tradução' - podemos prever mais esse trabalho árduo para o tradutor de Hirabô shigan para a língua portuguesa, de desvendar rastros talvez da literatura coreana? da literatura chinesa? da literatura grega? - na escrita de Kang. Algo que, por exemplo, percebi não ter acontecido na tradução da Lavoura Arcaica, de nosso grande Raduan Nassar, para o inglês, já a partir do título, como Ancient Tillage, o qual contribui, em conjunto com outras omissões e alterações, para o apagamento dos elos construídos na obra com outras tantas obras da literatura universal, e com a tradição helênica, nesse caso em particular. Já Berthold Zilly esteve atento a esses elos em sua tradução da mesma obra para o alemão, como sinalizo em Martins (2017) e o próprio tradutor aponta em Zilly (2009).

Tangemos, com isso, a questão da 'modernidade' em Meschonnic (2009). E como para este autor todos os conceitos se interligam, dentro de sua coerência teórica do apego ao modelo do contínuo, o moderno tem a ver com o poema, que tem a ver com a historicidade, que tem a ver com o recitativo, que tem a ver com o ritmo... De toda forma, para Meschonnic (2009), a obra literária se apresenta em sua plenitude de modernidade e de historicidade nessa medida, da revificação de outra(s) obra(s), de sua presentificação.

\footnotetext{
9 “Juntos subiam o grito de infortúnio e o clamor/ de vencedores e vencidos, e a terra jorrava sangue".

10 "Como é vivo esse sonho! 0 sangue corre e as lágrimas jorram".

TradTerm, São Paulo, v.38, fevereiro/2021, p. 22-45

Número Especial - III JOTA

www.revistas.usp.br/tradterm
} 
Kang está em busca do recitativo, da força da linguagem original, daquela linguagem da densidade do cristal. E sua personagem metonimicamente, ou dentro daquele jeu des mirroirs (KANG 2019: 62), ou no jogo de olhares que se espelham infinitamente - busca, em sua dimensão de cidadã coreana comum, em dramas do cotidiano de uma mulher em angústia e crise pela retomada da guarda de seu filho, a retomada da fala. Fala perdida, pelo que ela própria assevera, por algo que não seria tão simples como gostariam de supor as ponderações psicanalíticas: "Elle sait que la perte de la parole n'est pas due à une expérience particulière" ("Ela sabe que a perda da fala não se deve a uma experiência particular”) (KANG 2019: 166).

Algo passa pela perda e pela busca obstinada da retomada da capacidade de pronunciar palavras. Que, em última instância, envolve a capacidade humana de pensar e de atribuir valores próprios, autênticos, criativos. A ausência da linguagem - e mais especificamente da língua materna em sua capacidade criativa - conduz a uma visão fragmentária, caleidoscópica do mundo, em que tudo perde o sentido, este entendido como a capacidade de atribuir valores:

Comme elle a perdu l'usage de la parole, tout paysage est devenu une série de fragments nets. Comme les morceaux de papiers coloriés qui modifiaient d'un coup le motif, comme autant de pétales froids et muets dans le kaléidoscope (KANG 2019: 102). ${ }^{11}$

Podemos dizer - sem com isso pretender traçar qualquer relação de causa e efeito - que a ligação entre corpo e linguagem, à qual Meschonnic se refere reiteradamente, e que atribui a sua proposta a denominação de Antropologia da linguagem (MESCHONNIC 1982), é exemplificada, de forma contrastiva, no trecho reflexivo da personagem de Kang (2019: 104-105):

\author{
Je ne juge rien. \\ Je n'accorde aucun sentiment. \\ Tout vient en fragments, \\ se disperse toujours en fragments. Disparaît.
}

\footnotetext{
11 "Como perdeu o uso da palavra, toda a paisagem se transformou numa série de estilhaços. Como os pedaços de papeis coloridos que modificassem subitamente os motivos; como um monte de pétalas frias e mudas dentro do caleidoscópio".
}

TradTerm, São Paulo, v.38, fevereiro/2021, p. 22-45

Número Especial - III JOTA

www.revistas.usp.br/tradterm 
Les mots s'éloignent un peu plus du corps.

Comme des ombres lourdes superposées,

comme une puanteur, une nausée, détachent.

Des sentiments qui imprégnaient par un contact collant se inondés.

Comme des carrelages qui ne tiennent plus pour avoir été

Comme une partie de ma chair qui a pourri sans que je m'en rende compte. ${ }^{12}$

Passaremos, em seguida, ao breve estudo de trecho da carta 179 de Van Gogh e de sua tradução para a língua inglesa, no intuito de ainda completar alguns elementos da reflexão que venho tecendo em torno do ritmo e da panrítimica na obra de Henri Meschonnic.

\section{A carta 179: carta de Van Gogh a seu irmão Theo}

As cartas de Van Gogh (VAN Gogh Museum 2009) têm recebido diversas traduções, também aqui entre nós. O diferencial da proposta de Silveira (2020), no entanto, deu-se no fato da busca pela tradução literária, e do reconhecimento do valor literário dessas cartas que, via de regra, vêm atraindo a atenção dos estudiosos das artes e da História da Arte apenas em função de indícios que trariam sobre a biografia do autor e sobre diversos aspectos de sua personalidade.

Inclui-se, nesse caso, também, a atenção às cartas que versam sobre o amor do artista pela prima Kee, pelo tanto que se entende que o furor amoroso e a decepção amorosa devam ter exercido influência sobre sua dedicação à pintura e mesmo sobre o eventual aprimoramento dela. Por um interesse pessoal na temática, Silveira escolheu, de início, as quinze cartas dessa fase da vida do pintor holandês, e depois se deteve apenas na 179, considerando-a representativa das demais.

12 “Não julgo nada./Não atribuo nenhum sentimento./Tudo vem em fragmentos, / dispersa-se sempre em fragmentos. Desaparece./ As palavras se distanciam mais e mais de meu corpo./Como pesadas sombras superpostas,/como um fedor, uma náusea, /Os sentimentos impregnados em contato pegajoso se desprendem./Como telhas encharcadas que já não se sustentam./Como uma parte de minha carne que apodreceu sem que eu me desse conta".

TradTerm, São Paulo, v.38, fevereiro/2021, p. 22-45

Número Especial - III JOTA

www.revistas.usp.br/tradterm 
Foi, de toda forma, meu conhecimento do inglês e do alemão que contribuiu para que pudesse enxergar certas questões na escrita da carta em holandês, língua com a qual nunca tivera contato.

O paradigma indiciário costuma ser muito bem exemplificado pelo conto de Allan Poe, Os crimes da rua Morgue. Resumidamente, trata-se do caso em que todos os esforços racionais e técnicos dos policiais haviam sido malfadados, sem conseguirem a solução para o crime hediondo acontecido na pequena morada do segundo patamar de uma casa, onde residiam uma senhora de idade com sua sobrinha. Com sagacidade, o investigador Dupin, partindo de princípios mais intuitivos, dá atenção a certas particularidades que haviam passado despercebidas - e assim desvenda rapidamente o crime.

Intuição, certa sagacidade que não equivale, necessariamente, a habilidades de abstração, e a atenção a detalhes são alguns dos aspectos principais da proposta de Ginzburg (1989), que se baseou, por sua vez, em Giovani Morelli, historiador da arte.

Quando comecei a cotejar a carta de Van Gogh com a tradução para a língua inglesa, atentando para os detalhes naquela língua que eu desconhecia, encontrei logo na introdução o termo hart que aparecia traduzido em inglês por mind - sabendo-se que o inglês possui o vocábulo heart. Fui ao dicionário holandês/português, e confirmei que se tratava de coração. Era um pequeno e enorme detalhe: pequeno, porque seria apenas uma das centenas de palavras dessa carta; enorme, porque sinalizava a problemática da interpretação, que tanto Meschonnic (2006; 2008; 2009) renega: Interpretar=Hermenêutica; Traduzir=Poética. Também sinalizava, logo de início, a eventual tendência a um apagamento da emotividade, o que poderia estar traduzido, na sequência, no apagamento da informalidade e da afetividade que seriam de se esperar na carta entre dois irmãos.

Meschonnic esteve, sempre, em busca da proposta de uma Poética, Poética que, em seu enfoque do contínuo, passaria a se comunicar estreitamente com a Ética e com a Política, em substituição de algo que poderia se denominar Estética. A Poética seria mais abrangente do que a Estética, e não comportaria certo vício do apego a um belo, abstratamente

TradTerm, São Paulo, v.38, fevereiro/2021, p. 22-45

Número Especial - III JOTA

www.revistas.usp.br/tradterm 
definido, aos academicismos e aos esteticismos (MESCHONNIC 2009). A Poética envolve, sem dúvida, a busca do Bom, do Belo e do Justo, mas não em suas postulações platônicas, e principalmente não dentro das dicotomias e das descontinuidades. Ao contrário. Assim como o moderno, também o poético será o que nunca tem fim (MESCHONNIC 2009). O inacabado. De forma sempre materializada.

O problema da Hermenêutica está em sua tendência à interpretação: não traduz, interpreta. Esse foi o gesto do tradutor da língua inglesa, ao interpretar para seu leitor que o que o autor da carta queria dizer por hart seria mind. De alguma forma, ou ele viu em hart um anacronismo dentro de uma época mais racional, ou ele, de fato, teve aversão a certa emotividade excessiva, e a substituiu. O princípio da Hermenêutica é o da substituição, e envolve, também, conforme se pode pressupor, certo moralismo, ou seja, certa valoração positiva ou negativa desprovida de fundamentação ética, propriamente dita, mais sólida.

Acontece que uma problemática vai resvalando em outra, e com isso rui o castelo de cartas aparentemente tão bem montado. Porque, se a Hermenêutica tende a substituir em favor de um léxico em que encontraria um significado supostamente mais bem desenhado, há com isso o desmembramento significante/significado, a que Meschonnic atribui a denominação de 'signo'. Signo, no mundo meschonniciano, não é o signo propriamente dito, em sua completude, mas a fragmentação significante/significado (MESCHONNIC 2006a; 2010). De resto, todas as dicotomias e fragmentações - como oral/escrito, selvagem/civilizado, corpo/espírito - são alvo do ataque do linguista francês (que é enfático em não se dizer filósofo).

A Hermenêutica desconhece a força do significante - mas dizer isso ainda implicaria uma fragmentação, pela ênfase em uma das faces do signo, apenas. Melhor que isso será dizer que a Hermenêutica ignora o ritmo e a panrítmica. Vamos tentar entender esta.

A panrítmica é da ordem do contínuo, diz respeito aos versos, às frases, às estrofes, aos parágrafos. Para entendê-la ou apreendê-la, precisamos

TradTerm, São Paulo, v.38, fevereiro/2021, p. 22-45

Número Especial - III JOTA

www.revistas.usp.br/tradterm 
começar a desconfiar de nossas certezas de que cada palavra seria portadora, de forma autônoma, de um significado. Falar assim nos remete, em princípio, à proposta do linguista de Genebra, Ferdinand de Saussure, para quem as palavras formam sistema, e só dentro dele adquirem sentido, na medida em que adquirem valor. É digno de nota o fato de que Meschonnic (2006a; 2008; 2009) foi um defensor entusiasta do linguista suíço, cuja fertilidade do pensamento, em seu entender, teria sido reduzida e descaracterizada.

Talvez haja algo na mente humana que dificulte, mesmo, a apreensão de questões da ordem do contínuo, fazendo-nos tender, mais dia, menos dia, para as compartimentações, taxonomias, fragmentações. 0 certo é que, como bem destaca Meschonnic (2006), Saussure veio a ser conhecido como o fundador do estruturalismo, sendo que, de fato, seu pensamento seria voltado aos sistemas, e não às estruturas. Ou seja, não seria tendencialmente binário e dicotômico. Talvez por esse pontapé inicial direcionado às estruturas, passamos a dar mais atenção aos paradigmas, i.e., à relação das palavras umas com as outras dentro de um sistema ou estrutura virtual. O sintagma ficou ali relegado a mais um ponto teórico para os graduandos em Letras e Linguística: trata-se do eixo horizontal, dos encadeamentos. E daí?

Daí que, para entender a panrítmica, precisamos tirar o sintagma dessa ossificação em que permaneceu, e entendê-lo - ou entender, de preferência, a panrítmica - como aquilo que, embora não perceptível à primeira vista assim como o cordão do marinheiro, ou os pregos na janela, no caso de Os crimes da rua Morgue - é aquilo que atribui sentido, na medida em que "o ritmo é a organização da linguagem do contínuo de que somos feitos" (MESCHONNIC 2011: 165, tradução nossa). ${ }^{13}$

Possivelmente, também, é ele que nos faz perceber os tais sentidos das entrelinhas ou subliminares, os pressupostos e os subentendidos. Tudo está lá, para ser visto e percebido - de preferência, escutado. A escrita nos convoca para a escuta.

\footnotetext{
13 "rhythm is the language-organisation of the continuum of which we are made".
}

TradTerm, São Paulo, v.38, fevereiro/2021, p. 22-45

Número Especial - III JOTA

www.revistas.usp.br/tradterm 
A panrítmica não é algo do âmbito do abstrato, mas, sim, do âmbito do sugestivo, do alusivo. Ela se faz concretamente, de palavras. De palavras que agem em conjunto, todas de mãos dadas. Em decorrência disso, a Hermenêutica se torna venenosa para a Poética. Porque rompe esses laços, separa essas mãos, impede que se dê a propagação do ritmo. 0 ritmo é pan, é contínuo, generalizado, por isso mesmo não se trata, no caso, do ritmo métrico, que tenderia a localizá-lo em certos pontos de tonicidade.

Tendo percebido um primeiro indício da tendência à Hermenêutica na tradução das cartas de Van Gogh para o inglês - sem depreciá-la, mesmo porque toda tradução é tentativa - servimo-nos, de toda forma, dela, para irmos desvendando outras questões e refletindo sobre as possibilidades presentes na língua portuguesa frente à língua holandesa.

O cotejo é delicado, pois envolve não só o dito, mas o que poderia ter sido dito em seu lugar, ou seja, tudo aquilo da ordem paradigmática, virtual. Van Gogh escreve, no início:

\footnotetext{
Waarde Theo,

Er ligt me iets op't hart dat ik U vertellen wil. Misschien weet ge er reeds iets van \& vertel ik $U$ geen nieuws.
}

Traduzido em inglês por:

My dear Theo,

There's something on my mind that I want to tell you. Perhaps you already know something about it, and what I'm telling you isn't News (VAN GOGH MUSEUM 2009).

Para nossas escolhas para a língua portuguesa, ainda antes de ponderar sobre a panrítmica, necessitamos pensar sobre o lugar que Er ligt ocupa na língua holandesa frente a existe, há ou tem na língua portuguesa. 0 inglês opta por there's (poderia ter pensado em there exists), e me parece, em princípio, que, em nosso caso, precisaríamos do tem. Há, todavia, um me no holandês que torna a expressão bastante pessoal. Quem sabe poderíamos,

TradTerm, São Paulo, v.38, fevereiro/2021, p. 22-45

Número Especial - III JOTA

www.revistas.usp.br/tradterm 
então, conjugar o verbo ter - em lugar de deixá-lo impessoal - chegando a: Tenho comigo no coração algo que quero the contar ou Tenho algo em meu coração que quero lhe contar. Ou ainda: Tem uma coisa no meu coração que eu preciso lhe contar.

Note-se o quanto a segunda opção flui melhor que a primeira do ponto de vista da sonoridade da frase. Já a terceira opção possui um quê de mais proximidade. Nela 'precisar' passa a equivaler a 'querer', mesmo porque, na ordem do contínuo, certas fronteiras podem ser quebradas, de tal forma que 'querer' ou 'precisar' adquirem nuances muito próximas, sem que estejamos, com isso, pecando por excesso de interpretação. Estamos, assim, conseguindo, por assim dizer, ajustar a panrítmica.

A frase seguinte comporta novos desafios, particularmente na sequência ge er reeds, que me chama a atenção em sua tradução por already, em função do desmembramento vocabular na língua holandesa. Talvez uma partícula de ênfase seja necessária, como em 'já mesmo', e teríamos: Talvez você já saiba mesmo algo sobre isso \& eu não the conte nada de novo ou Talvez você já saiba alguma coisa disso tudo \& eu não the conte nada de novo, ou ainda: Talvez você já saiba alguma coisa disso tudo \& eu não esteja the contando nada de novo.

O uso de tudo nesta opção é bastante propício para mostrar o quanto o sentido não reside nas palavras isoladamente, pois ele não está presente no texto original em seu sentido dicionarizado em holandês, mas pode servir, em parte, para dar conta do aspecto enfático de ge, em parte para preencher a lacuna que ficaria vazia na falta de um equivalente para van.

Lembrando-se que as preposições em alemão e em holandês podem ser jogadas para o final da frase, como aconteceu nesse caso. Se quiséssemos achar uma construção em português semelhante a essa (no sentido de termos uma locução prepositiva ao final da primeira oração), poderíamos ter, nesse caso: Talvez você já saiba mesmo algo a esse respeito \& eu não the conte nada de novo. A escuta desta última frase, no entanto, faz-nos perceber certa artificialidade ou formalidade excessiva, que geraria falta de sintonia com o tom presente no texto, e com isso ruptura no ritmo.

TradTerm, São Paulo, v.38, fevereiro/2021, p. 22-45

Número Especial - III JOTA

www.revistas.usp.br/tradterm 
Assim, pareceu-me, de momento, que a segunda proposta seria a mais interessante nesse caso, embora a descoberta da terceira, com o gerúndio (ou o presente contínuo), tenha sido para mim, posteriormente, mais convincente. É fato que muitas vezes utilizamos em português o presente contínuo, quando as línguas anglo-saxônicas optam pelo presente simples.

Trata-se de certa ondulação da linguagem, que nos exige determinados preenchimentos em detrimento de outros, para cuja decisão a escuta será o único árbitro possível, e a escuta de quem esteja habituado a transitar com familiaridade na língua de chegada, em suas mais diversas manifestações. Também tenha um conhecimento razoável da língua de partida, do que the é gramatical e agramatical, assim como das valorações dos diferentes registros. Neste caso, gramáticas e dicionários especializados são de grande serventia. Parece-me, no entanto, que careceremos, ainda, de acervos e, mesmo, de aparelhagens que pudessem servir a tradutores como parâmetros para a escuta do ritmo e da panrítmica. Dependeremos, sempre, de um acervo guardado no corpo e na memória de cada um de nós?

\section{Alguns apontamentos à guisa de conclusão}

Ficam, aqui, assim, alguns apontamentos, em parte dirigidos à obra de Han Kang, em parte às cartas de Van Gogh, sempre tendo em mente a problemática da tradução. Para ambos os casos, destacou-se a necessidade da escuta, de que Kang trata dentro de um caso limite, em que a personagem praticamente recusa-se à fala, estando apenas em parte aberta à escuta, já que parece tender, apenas, à postura contemplativa de quem passa a se contentar com o olhar, porém um olhar que só the devolve uma realidade despedaçada.

Próximo ao final do romance, em situação de fragilidade do professor, que tivera seus óculos quebrados e aguardava o dia seguinte para poder ir buscar as lentes novas, ele dirige à jovem longos relatos de sua vida, em circunstância bastante pessoal e diferente daquela da sala de aula. Como sua eventual interlocutora nunca emite nenhum sinal de voz, a fim de confirmar que estaria sendo escutado, de quando em quando ele a interpela, e pode escutar alguns pequenos ruídos, que a jovem faz mexendo-se um pouco em TradTerm, São Paulo, v.38, fevereiro/2021, p. 22-45

Número Especial - III JOTA www.revistas.usp.br/tradterm 
seu assento de modo a dar-lhe uma resposta. No desenrolar da narrativa, veremos que, em certo momento, a comunicação se dará pela escrita, e, mais adiante, pela união - mesmo que efêmera - dos corpos.

Sem o apoio da língua falada, a realidade se mostra fragmentada, e podemos, agora, trazer essa ponderação para pensar sobre a forma com que as palavras na escritura se fragmentam à nossa frente, se desprovidas de nossa escuta, isto é, sempre que nos mostrarmos desatentos, negligentes, ou por algum motivo difícil de se explicar - incapazes de dar atenção a seu ritmo, que comporta, afinal, a própria vida que remanesce nas palavras. Elas perdem seu sentido naquilo que teriam de 'força da linguagem' (MESCHONNIC 2000), e junto com isso toda forma de valoração.

Enquanto na última obra publicada por Meschonnic em vida, datada de 2009, o autor contesta o sentido corriqueiro de modernidade, a partir de como se dá sua compreensão na Arquitetura, e convoca-nos para o entendimento da modernidade como pertencente ao inacabado, ao que nunca terá fim, fazendo isso de forma argumentativa, daquele jeito que o celebrizou como serial killer (DEGUY 2001), Kang parece nos apresentar a mesma questão dentro de realização linguística diversa, aquela que reconhecemos como literária. Vemos, por um lado, o cenário da grande metrópole, dos arranhacéus com seus letreiros alternantes, dos carros que cruzam velozes e luminosos as amplas avenidas, dos aparelhos celulares, todos formando o que poderíamos, equivocadamente, chamar de 'modernidade'. Por outro, a busca da palavra-cristal por aquela que perdeu a capacidade da fala, ou renunciou a ela. E é dela mesma que nos vem a ponderação de que "Nada cicatriza, nunca/ Nada nunca tem fim" (KANG 2019: 64).

Há muito o que se encontrar, que se desvelar, ainda, na obra de Kang, como também na escrita de Van Gogh, e é interessante, hoje, perceber o quanto pode contribuir para isso o trabalho do tradutor - mesmo que não seja perfeito, como nos adverte o professor de grego antigo (KANG 2019: 124). Nesse sentido, de resto, a tarefa do tradutor se apresenta, talvez, como o melhor exemplar da vocação para o provisório, para o tentativo, para o inacabado, para aquilo que está por vir, para o ainda desconhecido: $A$

TradTerm, São Paulo, v.38, fevereiro/2021, p. 22-45

Número Especial - III JOTA

www.revistas.usp.br/tradterm 
l'inconnu, conforme anuncia a epígrafe do livro de maior destaque de Henri Meschonnic (1982).

TradTerm, São Paulo, v.38, fevereiro/2021, p. 22-45

Número Especial - III JOTA

www.revistas.usp.br/tradterm 


\section{Referências}

Benjamin, W. A tarefa do tradutor. In: Escritos sobre mito e linguagem. São Paulo: Editora 34, 2011: 101-119.

CAMPOS, H. A língua pura na teoria da tradução de Walter Benjamin. Revista USP, São Paulo (33). Março/Maio, 1997: 161-170.

DeguY, M. Un serial killer: Henri Meschonnic. Sommaire, 165, Presses Universitaires de France, 2001: 110-112.

DeRRIDA, J. O monolinguismo do outro - Ou a prótese da origem. Porto: Campo das Letras, 2001.

GINZBURG, C. Mitos, emblemas e sinais: morfologia e história. São Paulo: Companhia das Letras, 1989.

KANG, H. Leçons de grec. Paris: Le Serpent à Plumes, 2019.

MARTINS, M. S. C. Ecos da Antígona na Lavoura de Nassar. Translatio. Porto Alegre: Universidade Federal do Rio Grande do Sul, 2017. http://seer.ufrgs.br/index.php/translatio/article/view/70434

MARTINS, M. S. C. A tradução como procedimento poético de repetição. Rónai: Revista de Estudos Clássicos e Tradutórios -V.6 N.1. Juiz de Fora: UFJF, 2018:72-83.

https://ronai.ufjf.emnuvens.com.br/ronai/article/view/250/170

MARTINS, M. S. C. O poder das palavras: em sua força poética, xamânica e tradutória. Campinas: Mercado de Letras, 2020.

MESCHONNIC, H. Critique du rythme: anthropologie historique du language. Paris: Verdier, 1982.

Meschonnic, H. Poétique du traduire. Paris: Verdier, 1999.

MesChONNIC, H. La force du langage. In: CHISS, J.-L.; Dessons, G. (Ed.). La force du langage. Rythme, discours, traduction. Autour de l'oeuvre d'Henri Meschonnic. Paris: Honoré Champion, 2000.

MesCHONNIC, H. La rime et la vie. Paris: Verdier, 2006a.

MESCHONNIC, H. Et la terre coule. Paris: Arfuyen, 2006b.

MesCHONnIC, H. Oui, qu'appelle-t-on penser? In: Dessons, G.; MARTIN, S.; Michon, P. Henri Meschonnic, la pensée et le poème. Paris: In Press, 2005.

MESCHONNIC, H. Dans le bois de la langue. Paris: Éditions Laurence Teper, 2008.

Meschonnic, H. Pour sortir du postmoderne. Paris: Klincksieck, 2009.

TradTerm, São Paulo, v.38, fevereiro/2021, p. 22-45

Número Especial - III JOTA

www.revistas.usp.br/tradterm 
Meschonnic, H. Poética do Traduzir. São Paulo: Perspectiva, 2010.

MeschonnIC, H. The Rhythm Party Manifesto. Thinking Verse I, 2011: 161-173.

SilveirA, N. V. G. Para ler Van Gogh: Tradução comentada da Carta 179 de Vincent van Gogh a seu irmão Theo. Dissertação de Mestrado. TRADUSP, 2020.

Van Gogh Museum. Van Gogh as a letter-writer: A new edition. Vincent van Gogh. The Letters. Amsterdam, 2009. Disponível em: http://vangoghletters.org/vg/letters/let179/letter.html. Acesso em $\underline{08 / 02 / 2020}$.

ZILLY, B. Lavoura arcaica "lavoura poética" lavoura tradutória: historicidade, atualidade e transculturalidade da obra-prima de Raduan Nassar. Estud.soc.agric, Rio de Janeiro, vol. 17, no. 1, 2009: 5-59.

Recebido em: 09/02/2020

Aceito em: 22/09/2020

Publicado em fevereiro de 2021

TradTerm, São Paulo, v.38, fevereiro/2021, p. 22-45

Número Especial - III JOTA

www.revistas.usp.br/tradterm 